\title{
Fluorescein Isothiocyanate Labeling Antigen-Based Immunoassay Strip for Rapid Detection of Acidovorax citrulli
}

Haijuan Zeng, Xuzhao Zhai, Manman Xie, and Qing Liu, ${ }^{\dagger}$ School of Medical Instrument and Food Engineering, University of Shanghai for Science and Technology, Shanghai 200093, China

\begin{abstract}
A simple and fast immunoassay strip to detect Acidovorax citrulli (Ac) using fluorescein isothiocyanate as a marker was developed. Fluorescein isothiocyanate (FITC) was added to sample culture medium for bacteria incubation, and the bacteria could emit a yellow-green fluorescence under ultraviolet light and become a fluorescent probe. This immunofluorescence strip (IFS) was based on the binding between fluorescent bacteria and the unlabeled monoclonal antibody $(\mathrm{McAb})$ immobilized on the test area in nitrocellulose membrane. The detection limit of the strip was $10^{6} \mathrm{CFU} / \mathrm{ml}$ with a result that could be observed within $10 \mathrm{~min}$. The IFS could detect eight strains of Ac and

display no cross-reactions with 30 other pathogenic strains. The detection results would not be affected by impurities in plant or unknown microorganisms in natural field samples and were consistent with PCR results, indicating that the IFS has high accuracy. This is the first report of using only one unlabeled $\mathrm{McAb}$ to develop a direct-type immunofluorescence strip for the rapid detection of Ac. The IFS reduced detection time and simplified operation procedures compared with the traditional enzyme-linked immunosorbent assay (ELISA) and PCR methods. In addition, this simple and inexpensive method will play a significant role in monitoring plant pathogens on field detection.
\end{abstract}

Bacterial fruit blotch (BFB) caused by gram-negative bacterium Acidovorax citrulli (Ac) is a devastating bacterial disease of watermelon and other cucurbits of the world. Since the first report in commercial products in 1965 (Webb and Goth 1965), BFB has caused millions of dollars of losses in many cucurbit products worldwide. As a seedborne pathogen, Ac can infect seeds, seedlings, and fruits, and infested seeds are the most important source for BFB outbreaks (Rane and Latin 1992). There are no commercial species that can completely resist BFB (Bahar et al. 2009). Hence, effective BFB management is early detection, diagnosis, and clearance of Ac for all commercial seeds and seedlings. At present, control measures for the disease are relatively backward, such as large-scale spraying of pesticides, which is unfriendly to the environment and pesticide residue is a threat to human health. There is an urgent need for a detection method to monitor the disease accurately to achieve the most efficient disease management (Rowlandson et al. 2015).

Routinely, PCR-based methods are considered as standard for pathogen detection. These assays such as multiplex PCR (Park and Ricke 2015), real-time PCR (Cho et al. 2015), multiplex real-time PCR (Delbeke et al. 2015), padlock probe amplification (Tian et al. 2013), and loop-mediated isothermal amplification (Mohon et al. 2016), are more efficient compared with culture-based methods, but the need for a sophisticated thermal cycler, professional operator, and a fully equipped laboratory limit the applicability and practicality in special places, e.g., on a farm. Immunological detection methods such as enzyme-linked immunosorbent assay (ELISA) (Zhong et al. 2012) and protein microarray (Castaneto et al. 2015) do not need any equipment, but the complicated operation steps are also time consuming.

Immunoassay strips usually use a nitrocellulose (NC) membrane as a carrier and a labeled antibody as the tracer. This method is convenient and provides one-step, rapid, and easily interpretable results. The most widely used format of strips is the application of colloidal gold as a tracer for visible detection. In recent years, new labels other than colloidal gold have been developed, such as upconversion

\section{${ }^{\dagger}$ Corresponding author: Qing Liu; E-mail: liuq@usst.edu.cn}

*The $\boldsymbol{e}$-Xtra logo stands for "electronic extra" and indicates that five supplementary figures are published online.

Accepted for publication 26 September 2017.

C 2018 The American Phytopathological Society fluorescent nanoparticles (Zhao et al. 2014), quantum dot (Berlina et al. 2013), and fluorescent microspheres (Chen et al. 2013). Note that these methods are commonly used to label antibodies, which heavily relied on the quality of labels used, e.g., the homogeneity of nanoparticle size and the coupling effect between the two antibodies. It is difficult to prepare the labels with good, stable performance. In addition, the pairing of monoclonal antibodies (McAbs) was another obstacle. In fact, due to the different properties and binding site of McAbs, not every McAb could be suitable for being labeled or paired with another antibody through corresponding antigen (Zeng et al. 2016). A double McAbs sandwich is the conventional mode for immunoassay strips, while the requirement for high specificity, easy pairing, and wide range of detection makes the methods very difficult to obtain or to have a satisfactory effect.

Fluorescein isothiocyanate (FITC), a fluorochrome dye, absorbs blue or ultraviolet light, causing molecules to become excited and emit a visible yellow-green light. As a fluorescent probe, FITC is widely used to trace drug delivery in vivo (Kim et al. 2009; Murányi et al. 2016), show the intracellular localization of pathogens (Saniee et al. 2013), estimate in vivo counts during passage of probiotics (Blajman et al. 2017), visualize live cells (Yeo et al. 2016), and so on. In this study, a novel immunofluorescence strip (IFS) using only one unlabeled antibody as test line was successfully developed. Specifically, modified brain heart infusion (BHI) medium containing FITC was first used to cultivate bacteria, and then signal amplification was realized by the target bacteria as a novel fluorescent probe after incubating with FITC. When FITC-Ac binds to antibodies coated on the test area, the accumulated FITC displays yellow-green light under ultraviolet light. Thus, a rapid, simple, and reliable test method was innovated and the detection theory is based on the fluorescent bacteria binding to the unlabeled antibody. The specificity, sensitivity, and stability of the strip were evaluated and the detection of real field samples were also demonstrated.

\section{Materials and Methods}

Bacterial strains and materials. The $\mathrm{McAb} 6 \mathrm{D}$ against $\mathrm{Ac}$ was prepared in our lab. BHI was purchased from Land Bridge (Beijing, China). The NC membrane, sample pad, and absorbent pad were purchased from Millipore (Bedford, MA, U.S.A.). FITC $\geq 90 \%$ (HPLC) and dimethyl sulfoxide (DMSO) were purchased from Sigma (St. Louis, MO, U.S.A.). Primes (Walcott and Gitaitis 2000) (WFB1: GACCA GCCACACTGGGAC; WFB2: CTGCCGTACTCCAGCGAT) were synthesized by Sangon (Shanghai, China). Strains used to evaluate the specificity of the strip were listed in Table 1. All solvents and other chemicals were analytical reagent grade. 
Bacteria culture. Modified BHI medium adding FITC dissolved in DMSO was used for bacterial culture. A single colony was added to modified BHI $(45 \mathrm{ml})$ containing a plant juice sample $(5 \mathrm{ml})$ and incubated at $37^{\circ} \mathrm{C}$ for $12 \mathrm{~h}$. Bacterial concentration was diluted by sterile saline and determined by plate count or by microplate reader (SpectraMax M2, Molecular Devices, Sunnyvale, CA, U.S.A.). The fluorescence intensity of bacteria was determined by flow cytometry (Becton Dickinson, Franklin Lakes, NJ, U.S.A.).

The optimum concentration of FITC. The concentration of the FITC solution for sample incubation could influence the background and the final fluorescence intensity of test line. Freshly prepared FITC solution was diluted to different concentrations of 10, 15, 20, 25, 30, 35, 40, $50,100,200,300$, and $400 \mu \mathrm{g} / \mathrm{ml}$ to culture Ac. After incubating, fluorescence intensity was detected by flow cytometry.

Fabrication and results judgment of direct IFS. The immunofluorescence strip consisted of a sample application pad, NC membrane, absorbent pad, and a backing card as shown in Figure 1A. The sample pad $(2.7 \times 30 \mathrm{~cm})$ was made of glass fiber, and the adsorbent pad $(3.2 \times$ $30 \mathrm{~cm}$ ) was made of cellulose fiber. The $6 \mathrm{D}$ were transferred onto the NC membrane $(2.5 \times 30 \mathrm{~cm})$ using an XYZ dispenser (Bio-Dot, Irvine, CA, U.S.A.) with a volume of $1 \mu \mathrm{l} / \mathrm{cm}$ and a dispensing rate of $4 \mathrm{~cm} / \mathrm{s}$ to form the test line. The blotted membrane, sample pad, and absorbent pad were assembled on the plastic backing board $(8 \times 30 \mathrm{~cm})$ sequentially with about $2 \mathrm{~mm}$ overlap. The assembly was cut into 3-mm-wide strips using a guillotine cutter (Bio-Dot) and then sealed in a plastic bag with desiccant and stored at room temperature.

When the samples were added dropwise to the sample pad, the complex FITC-Ac subsequently flowed through the NC membrane
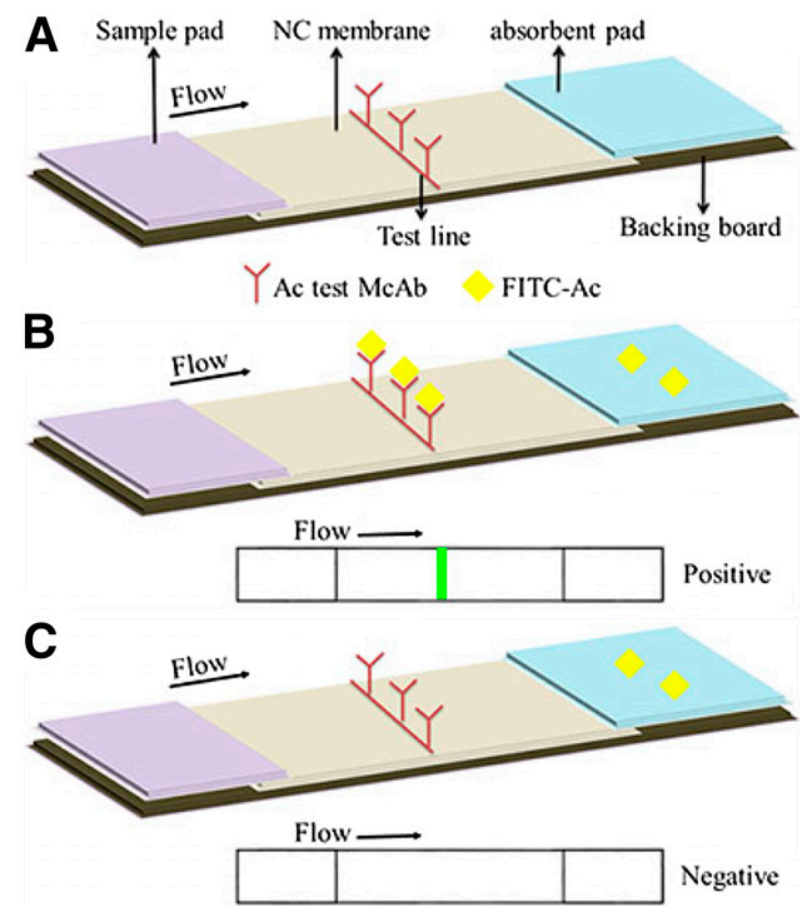

Fig. 1. A, Schematic representation of the test strip; B, positive result of the test strip; C, negative result of the test strip.

Table 1. Bacterial strains used in this study

\begin{tabular}{|c|c|c|c|}
\hline No. & Species/strains & Host & Origin \\
\hline 1 & Acidovorax citrulli SD01 & Watermelon & China \\
\hline 2 & Acidovorax citrulli ATCC 29625 & Watermelon & U.S.A. \\
\hline 3 & Acidovorax citrulli tw31 & Watermelon & China \\
\hline 4 & Acidovorax citrulli plsb91 & Melon & China \\
\hline 5 & Acidovorax citrulli xj112 & Cantaloupe & China \\
\hline 6 & Acidovorax citrulli 99-5 & Cantaloupe & U.S.A. \\
\hline 7 & Acidovorax citrulli PLSB1 & Melon & China \\
\hline 8 & Acidovorax citrulli $00-1$ & Watermelon & U.S.A. \\
\hline 9 & Acidovorax konjaci ATCC 33996 & Konjac & Japan \\
\hline 10 & Acidovorax cattleyae NCPPB 961 & $\ldots$ & $\ldots$ \\
\hline 11 & Acidovorax avenae ATCC 19307 & Sugarcane & Reunion \\
\hline 12 & Xanthomonas cucurbitae NCPPB 2597 & Curcurbita maxima & New Zealand \\
\hline 13 & Pseudomonas lachrymans NCPPB 540 & Cucumber & Denmark \\
\hline 14 & Erwinia tracheiphila NCPPB 2975 & Cucumber & U.S.A. \\
\hline 15 & Ralstonia soilanacearum $1.71 \#$ & Ginger & China \\
\hline 16 & Ralstonia soilanacearum $1.74 \#$ & Potato & China \\
\hline 17 & Ralstonia soilanacearum $1.76 \#$ & Casuarina & China \\
\hline 18 & Ralstonia soilanacearum $1000 \#$ & Tomato & China \\
\hline 19 & Ralstonia soilanacearum RS-5\# & Mulberry & China \\
\hline 20 & Xanthomonas axonopodis ATCC 11648 & Plant & U.S.A. \\
\hline 21 & Pseudomonas lachrymans NCPPB 277 & Cucumber & Denmark \\
\hline 22 & Clavibacter michiganense ATCC 14456 & Tomato & Italy \\
\hline 23 & Xanthomonas phaseoli ATCC 49119 & Phaseolus vulgaris & U.S.A. \\
\hline 24 & Curtobacterium flaccumfaciens DSM 20129 & Bean blight & U.S.A. \\
\hline 25 & Curtobacterium flaccumfaciens DSM 20135 & Seed of beans & U.S.A. \\
\hline 26 & Curtobacterium flaccumfaciens DSM 30886 & Plant & Netherlands \\
\hline 27 & Curtobacterium flaccumfaciens DSM 30885 & Plant & Netherlands \\
\hline 28 & Pseudomonas syringae BCCM LMG 5189 & Prunus domestica & Switzerland \\
\hline 29 & Pseudomonas syringae BCCM LMG 5083 & Betula pendula & New Zealand \\
\hline 30 & Bacillus thuringiensis ATCC 10792 & $\ldots$ & $\ldots$ \\
\hline 31 & Bacillus subtilis ATCC 6633 & $\ldots$ & $\ldots$ \\
\hline 32 & Bacillus subtilis ATCC 9372 & $\ldots$ & $\ldots$ \\
\hline 33 & Bacillus cereus CMCC(B) 63303 & $\ldots$ & $\ldots$ \\
\hline 34 & Bacillus cereus $\mathrm{CMCC}(\mathrm{B}) 63301$ & $\ldots$ & $\ldots$ \\
\hline 35 & Bacillus pumilus CMCC(B) 63202 & $\ldots$ & \\
\hline 36 & Bacillus mycoides ATCC 10206 & $\ldots$ & $\ldots$ \\
\hline 37 & Escherichia coli ATCC 8739 & Feces & $\ldots$ \\
\hline 38 & Escherichia coli ATCC 25922 & $\ldots$ & $\ldots$ \\
\hline
\end{tabular}


via capillary action. When the complex passed the test line on which $6 \mathrm{D}$ was immobilized, the FITC-Ac bound to $6 \mathrm{D}$, forming a tripolymer FITC-Ac-McAb. Accumulative FITC displayed yellowgreen fluorescence under ultraviolet light (Fig. 1B). If there was no Ac in the samples, the FITC did not accumulate on the test line (Fig. 1C).

Sensitivity, stability, and specificity of the IFS. To evaluate the sensitivity of the strip, $10^{5}$ to $10^{8} \mathrm{CFU} / \mathrm{ml}$ concentrations of SD01 were analyzed with the IFS. Ac detection was carried out by applying $75 \mu \mathrm{l}$ sample solution to the sample pad of the strip. Modified BHI medium containing FITC was used as negative control. After $10 \mathrm{~min}$, the results of test line were visualized in a black box equipped with an ultraviolet light source and a fluorescent filter of $525 \mathrm{~nm}$ (Semrock, Rochester, NY, U.S.A.) and then recorded with a digital camera.

The IFS was stored at room temperature for 1, 2, 3, and 4 months to assess stability by evaluating the sensitivity of the strip. The SD01 of
$10^{6} \mathrm{CFU} / \mathrm{ml}$ were used to analyze the stability of the IFS. The same test was conducted as described above.

Eight strains of Ac (SD01, ATCC 29625, 99-5, xj112, PLSB1, 00-1, plsb91, tw31) and 30 pathogenic strains that could infect plants or exist in soil, were cultured in modified BHI medium and used to evaluate the specificity of the strip. All bacterial suspensions were adjusted to the same concentrations using microplate reader.

Simulated samples detection. The Ac-free plant samples including watermelon, muskmelon, cantaloupe, pumpkin, cucumber, luffa, wax gourd, and summer squash, which were verified by PCR, were purchased from the field. These juice samples $(5 \mathrm{ml})$ added to the modified BHI ( $45 \mathrm{ml})$ containing FITC were used to cultivate strain SD01. These inoculums were diluted to $10^{6} \mathrm{CFU} / \mathrm{ml}$ for strip detection. The purpose of the test was to determine whether the matrix in the juice from the plants could impact the smallest detectable concentration.
A
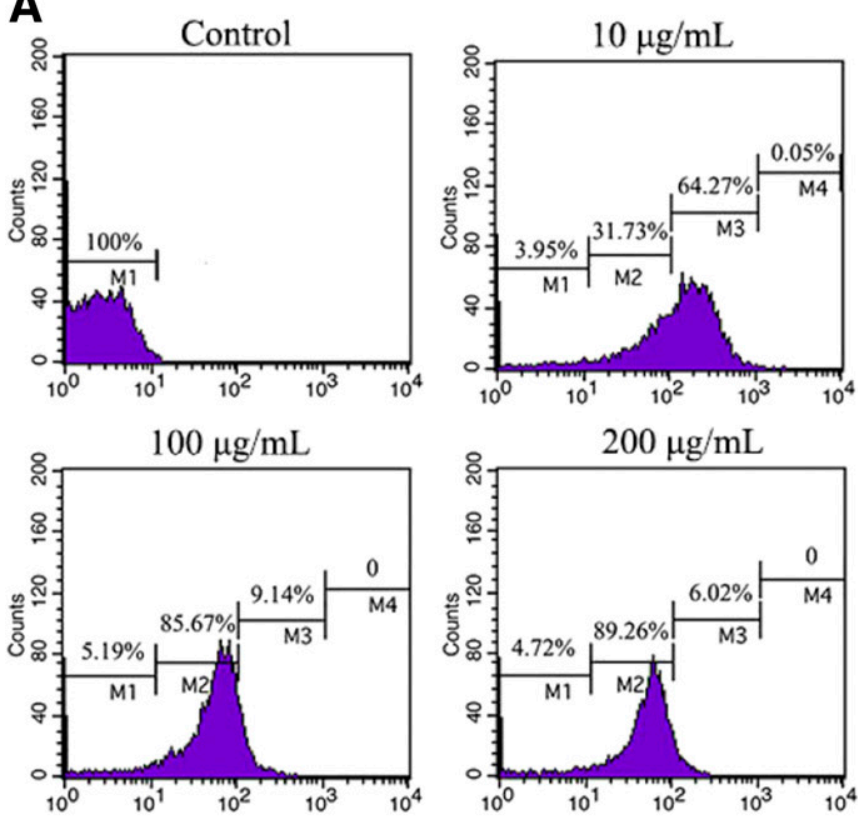

B
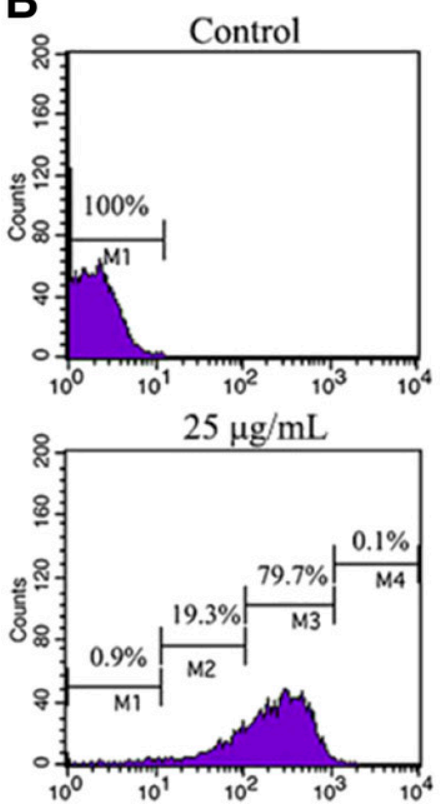
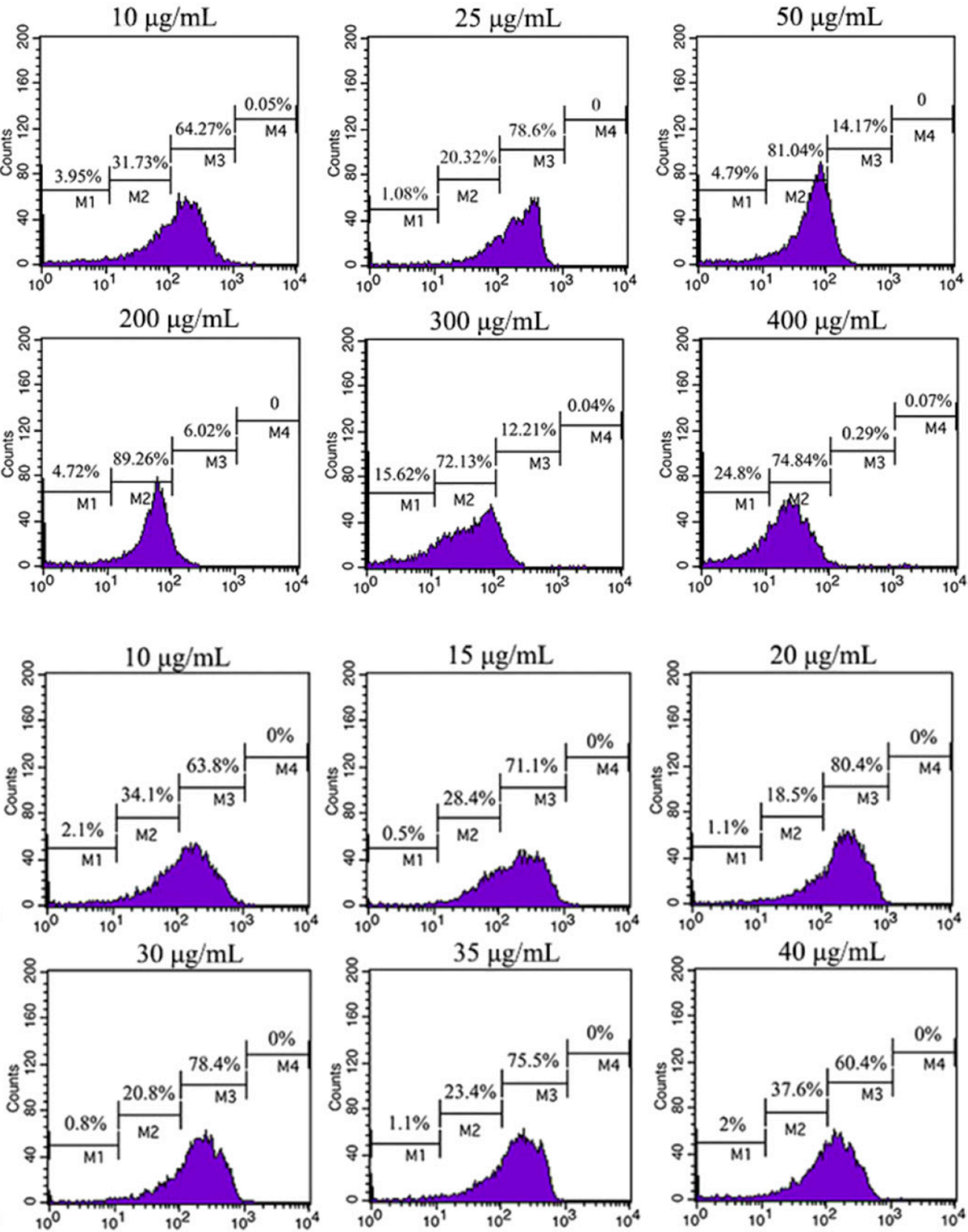

Fig. 2. The fluorescence intensity at different fluorescein isothiocyanate (FITC) concentrations detected by flow cytometry. A, Optimization FITC concentrations of $10,25,50,100$, 200,300 , and $400 \mu \mathrm{g} / \mathrm{ml}$. B, Optimization FITC concentrations of 10, 15, 20, 25, 30, 35, and $40 \mu \mathrm{g} / \mathrm{ml}$. M1: Bacterial distribution with fluorescence intensity of 1 to 10; M2: bacterial distribution with fluorescence intensity of 10 to $10^{2}$; M3: bacterial distribution with fluorescence intensity of $10^{2}$ to $10^{3}$; M4: bacterial distribution with fluorescence intensity of $10^{3}$ to $10^{4}$. 
Real samples detection. Natural watermelon samples including 13 samples of watermelon plants collected from local field and 13 samples of watermelon seeds purchased from different markets were analyzed using the IFS test and then confirmed with the PCR method. Another six samples of diseased watermelon plants collected from the field were analyzed by the IFS.

\section{Results}

Optimization of parameters. To develop the strip, many factors should be optimized to increase sensitivity. Different FITC concentrations of $10,25,50,100,200,300$, and $400 \mu \mathrm{g} / \mathrm{ml}$ were first chosen to culture Ac and then detected by flow cytometry. As shown in Figure 2, the abscissa represent the fluorescence intensity. The percentage of fluorescent bacteria (M2+M3+M4) and the bacterial distribution in M2, M3, and M4 areas at different FITC concentrations were different. It is noteworthy that fluorescence intensity played a decisive role in the sensitivity of the test strip. Thus, the proportion of the distribution in the M3 region was chosen as the basis for determining the optimum FITC concentration. From Figure 2A, the percentage of fluorescent bacteria in the $\mathrm{M} 3$ region was higher than others when the FITC concentration was $25 \mu \mathrm{g} / \mathrm{ml}$.

Then, another series of FITC concentrations (10, 15, 20, 25, 30, 35, and $40 \mu \mathrm{g} / \mathrm{ml}$ ) were chosen to culture Ac. As shown in Figure

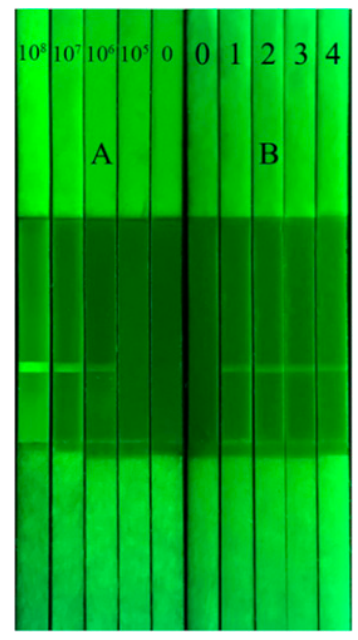

Fig. 3. The performance of the designed immunofluorescence strip (IFS). A, Sensitivity of the IFS (SD01 concentrations from $10^{8}$ to $10^{5} \mathrm{CFU} / \mathrm{ml}$ ); B, stability of the IFS by evaluating the sensitivity in $10^{6} \mathrm{CFU} / \mathrm{ml}$ after storing at room temperature. 0: Blank control using modified brain heart infusion medium; B1: after 1 month; B2: after 2 months; B3: after 3 months; B4: after 4 months.
2B, $20 \mu \mathrm{g} / \mathrm{ml}$ was considered to be the optimal FITC concentration for detection. Supplementary Figure S1 shows the morphological picture of Ac cultured with FITC viewed under a fluorescent microscope with blue light. After incubating with FITC, the bacteria became a fluorescent probe.

The concentration of McAb 6D is important for the performance of the IFS; the color of the test line deepened with increasing concentration of $6 \mathrm{D}$. However, the blank control using the modified BHI medium had a false-positive result when the McAb 6D concentration was higher than $2 \mathrm{mg} / \mathrm{ml}$ (as shown in Supplementary Fig. S2). Thus, the optimal concentration of McAb 6D was determined to be $2 \mathrm{mg} / \mathrm{ml}$.

Sensitivity and stability of the IFS. To identify the sensitivity of the IFS, a diluted gradient of SD01 $\left(10^{5}\right.$ to $\left.10^{8} \mathrm{CFU} / \mathrm{ml}\right)$ were added to the sample pad of the strip, respectively. As shown in Figure 3A, the yellow-green light of the test line was evident for concentrations ranging from $10^{6}$ to $10^{8} \mathrm{CFU} / \mathrm{ml}$. When the concentration was below $10^{5} \mathrm{CFU} / \mathrm{ml}$, no lines were observed. The test indicated that the detection limit was considered to be $10^{6} \mathrm{CFU} / \mathrm{ml}$.

The IFS was stored at room temperature for 1, 2, 3, and 4 months to assess their stability by evaluating the sensitivity of the strip in $10^{6} \mathrm{CFU} / \mathrm{ml}$. As shown in Figure 3B, the strips (1 to 4) showed positive results indicating that the strips could be stored for at least 4 months without losing their stability.

Specificity of the IFS. Since the common antigen of most bacteria, including Ac, is still unknown, the detection of different serotypes to evaluate the specificity of the IFS is critically important. We evaluated the IFS using eight strains of Ac and 30 pathogenic strains (listed in Table 1) that could infect plants or exist in soil. As shown in Figure 4, eight strains of Ac (IFS 1 to 8) demonstrated a positive result, indicating that the IFS could detect all of the tested Ac strains, and other strains (IFS 9 to 38) produced negative results, indicating the high specificity of the IFS for Ac.

Simulated sample analysis. In order to ensure the applicability and accuracy of the strip in real samples, a single colony of SD01 was added to $45 \mathrm{ml}$ of modified BHI containing $5 \mathrm{ml}$ of juice squeezed from eight species of cucurbitaceous plants including watermelon, cantaloupe, muskmelon, pumpkin, cucumber, luffa, wax gourd, and summer squash and incubated at $37^{\circ} \mathrm{C}$ for $12 \mathrm{~h}$. Then, the inoculums were diluted to $10^{6} \mathrm{CFU} / \mathrm{ml}$ to simulate Ac infection. As shown in Figure 5, all Ac samples presented positive results, which indicated that the impurities in plant juice would not impact the detection results and the smallest detectable concentration in real samples was $10^{6} \mathrm{CFU} / \mathrm{ml}$, which were consistent with PCR results (Supplementary Figure S3).

Real samples detection. As displayed in Figure 6A, only one seed sample tested positive and others were negative, which was consistent with the result of PCR methods (Supplementary Figure S4). As shown in Figure 6B, the detection results of the six diseased

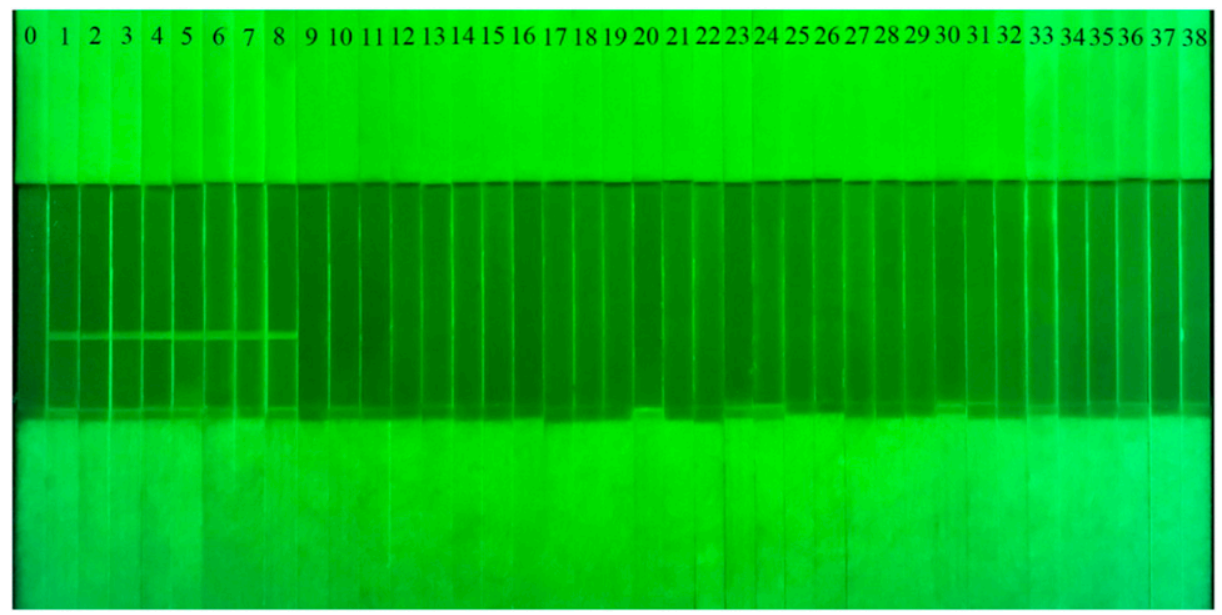

Fig. 4. The specificity of the immunofluorescence strip. 0: Blank control using modified brain heart infusion medium; 1 to 8: Acidovorax citrulli strains; 9 to 38 : other strains listed in Table 1 from 9 to 38. 
watermelon samples were all positive (consistent with PCR result, Supplementary Figure S5), indicating that the unknown microorganisms did not cause false positive results, and the IFS was specific to detect Ac with high accuracy and applicable to the detection of real field samples.

\section{Discussion}

In this study, we developed a novel labeling method in which FITC was used to make bacteria fluoresce during bacterial enrichment process. This antigen-labeling method in vivo could make the bacteria emit stable and bright fluorescence and not quench after the bacteria enter the cell (Blajman et al. 2017; Hu et al. 2012). Further, an immunofluorescence strip, independent on antibody labeling and double antibody pairing, was developed based on the fluorescent bacteria binding to the unlabeled $\mathrm{McAb}$ coated on the test line and accumulated FITC displayed yellow-green fluorescence.

The widely used diagnosis methods for Ac were instruments based assays, e.g., PCR-based assays (Tian et al. 2016; Wu et al. 2017), surface plasmon resonance imaging (Puttharugsa et al. 2011), and mass spectrometry (Kajiwara et al. 2012; Wang et al. 2012), requiring a series of reagents or a professional technician, limiting the application in certain places. In addition, immunological assays including ELISA, microarray, and immunoassay strips were also used for the detection of Ac and other bacterial phytopathogens. The complicated steps and long incubation time hindered the use of ELISA and microarray (Safenkova et al. 2016; Thaitrong et al. 2013). The immunoassay based on microsphere or other fluorescent nanomaterials could be used for multiplex screening while the assay time $(1 \mathrm{~h})$ was longer than our developed strip (10 min) (Charlermroj et al. 2013). Colloidal gold-

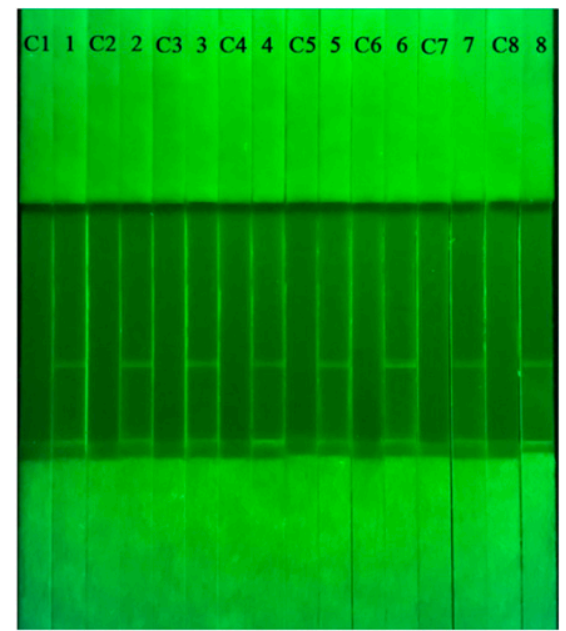

Fig. 5. Detection results of simulated samples. 1: Watermelon; 2: cantaloupe; 3 : muskmelon; 4: pumpkin; 5: cucumber; 6: luffa; 7: wax gourd; 8: summer squash; C1 to C8: corresponding juice without SD01.
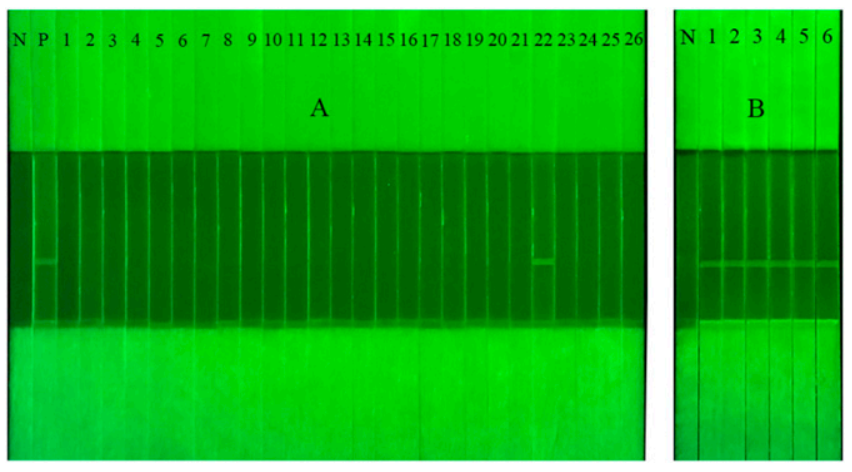

Fig. 6. Detection results for real field samples using the designed strip. N: Negative control; P: positive control; $A 1$ to $A 13$ : natural watermelon plant samples; $A 14$ to A26: watermelon seed samples; B1 to B6: diseased watermelon samples. based immunoassay strips used a pair of monoclonal antibodies, which were heavily dependent on the quality and coupling effect of the two antibodies (Feng et al. 2015; Panferov et al. 2016). The nucleic acid hybridization-based strip possessed high sensitivity while the process of pretreating bacterial samples to obtain DNA was complex and laborintensive (Zhao et al. 2011).

Compared with the methods mentioned above, the cost of our developed strip is low, as it eliminates the need for two antibodies in usual immunoassay strips to form a double antibody sandwich and the FITC material is cheaper than other labelers, such as upconversion nanoparticles (Zhang et al. 2016), lanthanide fluorescent nanoparticles (Zhang et al. 2014), and so on, and all of these will make this method more popular. Meanwhile, according to the accuracy and stability analyses performed in our study, FITC showed robust stability compared with colloidal gold particles since the chemical and colloidal instability in biological environment may lead to inaccurate results (Qu et al. 2016). Although the strip developed in this study still needs further improvement due to the lower sensitivity compared with instrument-based methods, it is simpler, faster, and appropriate for use by a nonspecialist, or in places where the facilities are not available.

Due to the long survival time in the seeds (Block and Shepherd 2008), fast reproduction, and spread, $0.01 \%$ of contaminated seeds could cause disease occurrence and epidemic (Rane and Latin 1992), and even seeds from symptomless fruit may carry pathogens (Hopkins and Thompson 2002), which all lead substantial economic losses to growers and processors. Moreover, Ac has many potential hosts, which could be carried by the seeds of solanaceous plants (Assouline et al. 1997) or spread through the weeds of citronmelon (Isakeit et al. 1998). To improve the monitoring and early warning capacity of $\mathrm{BFB}$, growers need to strengthen pathogen quarantine to diagnose earlier and dispose of pathogens promptly through biological or chemical means. Encouragingly, the IFS could be used for real-time monitoring thanks to its ease of operation, accuracy, and convenience, which provide great application potential for quality control of watermelon fruits and pathogen quarantine of seeds or seedlings.

\section{Acknowledgments}

This research is supported by Natural Science Foundation of China (No. 31371776), Science and technology innovation plan of Shanghai: Yangtze River Delta joint research (No. 15395810900), Minimally Motivated Innovation Fund (YS30809102), and Graduate Education Innovation Program of Shanghai.

\section{Literature Cited}

Assouline, I., Milshtein, H., Mizrahi, M., Levy, E., and Ben-Ze'Ev, I. S. 1997 Acidovorax avenae subsp. citrulli transmitted by solanaceous seeds. Phytoparasitica 25:117-118.

Bahar, O., Kritzman, G., and Burdman, S. 2009. Bacterial fruit blotch of melon: screens for disease tolerance and role of seed transmission in pathogenicity. Eur. J. Plant Pathol. 123:71-83.

Berlina, A. N., Taranova, N. A., Zherdev, A. V., Vengerov, Y. Y., and Dzantiev, B. B. 2013. Quantum dot-based lateral flow immunoassay for detection of chloramphenicol in milk. Anal. Bioanal. Chem. 405:4997-5000.

Blajman, J. E., Astesana, D. M., Zimmermann, J. A., Rossler, E., Scharpen, A. R., Berisvil, A. P., Zbrun, M. V., Soto, L. P., Rosmini, M. R., and Frizzo, L. S. 2017. Quantification of FITC-labelled probiotic Lactobacillus salivarius DSPV 001P during gastrointestinal transit in broilers. Benef. Microbes 8:55-64.

Block, C., and Shepherd, L. M. 2008. Long-term survival and seed transmission of Acidovorax avenae subsp. citrulli in melon and watermelon seed. Plant Health Prog. 99:S229.

Castaneto, M. S., Barnes, A. J., Concheiro, M., Klette, K. L., Martin, T. A., and Huestis, M. A. 2015. Biochip array technology immunoassay performance and quantitative confirmation of designer piperazines for urine workplace drug testing. Anal. Bioanal. Chem. 407:4639-4648.

Charlermroj, R., Himananto, O., Seepiban, C., Kumpoosiri, M., Warin, N., Oplatowska, M., Gajanandana, O., Grant, I. R., Karoonuthaisiri, N., and Elliott, C. T. 2013. Multiplex detection of plant pathogens using a microsphere immunoassay technology. PLoS One 8:e62344.

Chen, R., Li, H., Zhang, H., Zhang, S., Shi, W., Shen, J., and Wang, Z. 2013. Development of a lateral flow fluorescent microsphere immunoassay for the determination of sulfamethazine in milk. Anal. Bioanal. Chem. 405:6783-6789.

Cho, M. S., Park, D. H., Ahn, T. Y., and Park, D. S. 2015. Rapid and specific detection of Acidovorax avenae subsp. citrulli using SYBR green-based real-time PCR amplification of the YD-repeat protein gene. J. Microbiol. Biotechnol. 25:1401-1409. 
Delbeke, S., Ceuppens, S., Holvoet, K., Samuels, E., Sampers, I., and Uyttendaele, M. 2015. Multiplex real-time PCR and culture methods for detection of Shiga toxin-producing Escherichia coli and Salmonella Thompson in strawberries, a lettuce mix and basil. Int. J. Food Microbiol. 193:1-7.

Feng, M., Kong, D., Wang, W., Liu, L., Song, S., and Xu, C. 2015. Development of an immunochromatographic strip for rapid detection of Pantoea stewartii subsp. stewartii. Sensors (Basel) 15:4291-4301.

Hopkins, D. L., and Thompson, C. M. 2002. Seed transmission of Acidovorax avenae subsp. citrulli in cucurbits. HortScience 37:924-926.

Hu, C. S., Chiao-Hsi, C., Hong, P. D., and Ming-Kung, Y. 2012. Influence of charge on FITC-BSA-loaded chondroitin sulfate-chitosan nanoparticles upon cell uptake in human Caco-2 cell monolayers. Int. J. Nanomedicine 2012:4861-4872.

Isakeit, T., Black, M. C., and Jones, J. B. 1998. Natural infection of Citronmelon with Acidovorax avenae subsp. citrulli. Plant Dis. 82:351.

Kajiwara, H., Sato, M., and Suzuki, A. 2012. Detection of Acidovorax avenae subsp. citrulli using PCR and MALDI-TOF MS. J. Electrophor. 56:13-17.

Kim, B. S., Oh, J. M., Kim, K. S., Seo, K. S., Cho, J. S., Khang, G., Lee, H. B., Park, K., and Kim, M. S. 2009. BSA-FITC-loaded microcapsules for in vivo delivery. Biomaterials 30:902-909.

Mohon, A. N., Lee, D. Y., Bayih, A. G., Folefoc, A., Guelig, D., Burton, R. A., Labarre, P., Chan, W., Meatherall, B., and Pillai, D. R. 2016. NINA-LAMP compared to microscopy, RDT, and nested PCR for the detection of imported malaria. Diagn. Microbiol. Infect. Dis. 85:149-153.

Murányi, J., Gyulavári, P., Varga, A., Bökönyi, G., Tanai, H., Vántus, T., Pap, D., Ludányi, K., Mez, G., and Kéri, G. 2016. Synthesis, characterization and systematic comparison of FITC-labelled GnRH-I, -II and -III analogues on various tumour cells. J. Pept. Sci. 22:552-560.

Panferov, V. G., Safenkova, I. V., Varitsev, Y. A., Drenova, N. V., Kornev, K. P., Zherdev, A. V., and Dzantiev, B. B. 2016. Development of the sensitive lateral flow immunoassay with silver enhancement for the detection of Ralstonia solanacearum in potato tubers. Talanta 152:521.

Park, S. H., and Ricke, S. C. 2015. Development of multiplex PCR assay for simultaneous detection of Salmonella genus, Salmonella subspecies I, Salm. Enteritidis, Salm. Heidelberg and Salm. Typhimurium. J. Appl. Microbiol. 118:152-160.

Puttharugsa, C., Wangkam, T., Huangkamhang, N., Gajanandana, O., Himananto, O., Sutapun, B., Amarit, R., Somboonkaew, A., and Srikhirin, T. 2011. Development of surface plasmon resonance imaging for detection of Acidovorax avenae subsp. citrulli (Aac) using specific monoclonal antibody. Biosens. Bioelectron. 26:2341-2346.

Qu, H., Zhang, Y., Qu, B., Kong, H., Qin, G., Liu, S., Cheng, J., Wang, Q., and Zhao, Y. 2016. Rapid lateral-flow immunoassay for the quantum dot-based detection of puerarin. Biosens. Bioelectron. 81:358-362.

Rane, K. K., and Latin, R. X. 1992. Bacterial fruit blotch of watermelon: association of the pathogen with seed. Plant Dis. 76:509-512.

Rowlandson, T., Gleason, M., Sentelhas, P., Gillespie, T., Thomas, C., and Hornbuckle, B. 2015. Reconsidering leaf wetness duration determination for plant disease management. Plant Dis. 99:310-319.

Safenkova, I. V., Pankratova, G. K., Zaitsev, I. A., Varitsev, Y. A., Vengerov, Y. Y., Zherdev, A. V., and Dzantiev, B. B. 2016. Multiarray on a test strip
(MATS): rapid multiplex immunodetection of priority potato pathogens. Anal. Bioanal. Chem. 408:6009-6017.

Saniee, P., Siavoshi, F., Nikbakht, B. G., Khormali, M., Sarrafnejad, A., and Malekzadeh, R. 2013. Localization of H.pylori within the vacuole of Candida yeast by direct immunofluorescence technique. Arch. Iran Med. 16: 705-710.

Thaitrong, N., Charlermroj, R., Himananto, O., Seepiban, C., and Karoonuthaisiri, N. 2013. Implementation of microfluidic sandwich ELISA for superior detection of plant pathogens. PLoS One 8:e83231.

Tian, Q., Feng, J.-J., Hu, J., and Zhao, W.-J. 2016. Selective detection of viable seed-borne Acidovorax citrulli by real-time PCR with propidium monoazide. Sci. Rep. 6:35457.

Tian, Y., Zhao, Y., Walcott, R. R., Hu, B., Liu, F., Tian, Y., Zhao, Y., Hu, B., and Liu, F. 2013. Reliable and sensitive detection of Acidovorax citrulli in cucurbit seed using a padlock-probe-based assay. Plant Dis. 97:961-966.

Walcott, R. R., and Gitaitis, R. D. 2000. Detection of Acidovorax avenae subsp. citrulli in watermelon seed using immunomagnetic separation and the polymerase chain reaction. Plant Dis. 84:470-474.

Wang, Y., Zhou, Q., Li, B., Liu, B., Wu, G., Ibrahim, M., Xie, G., Li, H., and Sun, G. 2012. Differentiation in MALDI-TOF MS and FTIR spectra between two closely related species Acidovorax oryzae and Acidovorax citrulli. BMC Microbiol. 12:182.

Webb, R. E., and Goth, R. W. 1965. A seedborne bacterium isolated from watermelon. Plant Dis. Report. 49:818-821.

Wu, P. Y., Ho, L. C., Chang, J. J., Tzeng, K. C., Deng, W. L., and Lin, Y. H. 2017. Development of a TaqMan probe-based insulated isothermal PCR (TiiPCR) for the detection of Acidovorax citrulli, the bacterial pathogen of watermelon fruit blotch. Eur. J. Plant Pathol. 147:869-875.

Yeo, K. B., Kim, H. B., Choi, Y. S., and Pack, S. P. 2016. Highly effective detection of inflamed cells using a modified bradykinin ligand labeled with FITC fluorescence. Enzyme Microb. Technol. 82:191-196.

Zeng, H., Guo, W., Liang, B., Li, J., Zhai, X., Song, C., Zhao, W., Fan, E., and Liu, Q. 2016. Self-paired monoclonal antibody lateral flow immunoassay strip for rapid detection of Acidovorax avenae subsp. citrulli. Anal. Bioanal. Chem. 408:6071-6078.

Zhang, B., Li, H., Pan, W., Chen, Q., Ouyang, Q., and Zhao, J. 2016. Dualcolor upconversion nanoparticles (UCNPs)-based fluorescent immunoassay probes for sensitive sensing foodborne pathogens. Food Anal. Methods 10:2036-2045.

Zhang, F., Zou, M., Chen, Y., Li, J., Wang, Y., Qi, X., and Xue, Q. 2014 Lanthanide-labeled immunochromatographic strips for the rapid detection of Pantoea stewartii subsp. stewartii. Biosens. Bioelectron. 51:29-35.

Zhao, P., Wu, Y., Zhu, Y., Yang, X., Jiang, X., Xiao, J., Zhang, Y., and Li, C. 2014. Upconversion fluorescent strip sensor for rapid determination of Vibrio anguillarum. Nanoscale 6:3804-3809.

Zhao, W., Lu, J., Ma, W., Xu, C., Kuang, H., and Zhu, S. 2011. Rapid on-site detection of Acidovorax avenae subsp. citrulli by gold-labeled DNA strip sensor. Biosens. Bioelectron. 26:4241-4244.

Zhong, F., Wang, Y., Li, L. R., Huang, H. Y., Song, Y., Yang, Z. X., and Yao, X. P. 2012. Isolation and identification of Haemophilus parasuis and establishment of its detection method of indirect ELISA. J. Anim. Vet. Adv. 11:2384-2391. 